\title{
The naughty knot in catheterisation laboratory
}

\author{
Himanshu Mahla, Sunil Kumar Kondethimmanahally Rangaiah, D Ramesh, \\ Cholenahally Nanjappa Manjunath
}

Department of Cardiology, Sri Jayadeva Institute of

Cardiovascular Sciences and

Research, Bangalore,

Karnataka, India

\section{Correspondence to}

Dr Sunil Kumar

Kondethimmanahally

Rangaiah,

drsunilkumarkr@gmail.com

Accepted 3 May 2014

\section{CrossMark}

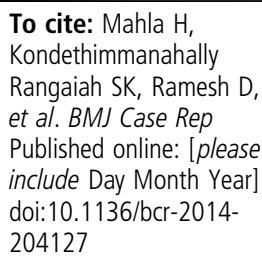

\section{DESCRIPTION}

A 60-year-old man presented to the emergency department with multiple syncopal episodes. A 12-lead ECG revealed complete heart block with a ventricular rate of $50 \mathrm{bpm}$ (figure 1). Emergency temporary pacing was performed through the transjugular route without fluoroscopic guidance (as the patient arrived at our institute at night) and ventricular capture confirmed (figure 2). The patient did well overnight but at the time of morning rounds he started having giddiness again. ECG showed complete heart block with no pacing spikes. The patient was taken to the catheterisation laboratory. Flouroscopy revealed a knot in the pacing lead (figure 3, video 1). Emergency pacing was achieved through the transfemoral route. Now we planned to unknot 'the naughty knot'. We tried to manipulate the lead through the jugular route but this was unsuccessful. Ultimately we took a $0.035^{\prime \prime} \mathrm{J}$ tipped guide wire (Terumo Interventional Systems). We approached the knot through the femoral route and the knot was opened by hooking the J tip in it and the lead was retrieved successfully (figure 4, video 2). Knotting of an intravascular catheter was first reported by Johansson et al in 1954. ${ }^{1}$ Knotting together of temporary and permanent pacemaker leads has also been described. ${ }^{2}$ Various methods of unknotting can be used, for example, putting a long sheath through the same route and covering the knot with the sheath, ${ }^{3}$ which was unfortunately unavailable in our laboratory that day. Other methods can be: snares-either commercial or indigenous, retrieval baskets, endomyocardial biopsy forceps and angioplasty balloon inflation. Knotting of intravascular devices like catheters or leads is a rare complication but a significant cause of morbidity. Unknotting can be performed percutaneously in most cases but surgical retrieval is required in some cases with extensive knots with large lengths or when the knot is intracardiac fixed. Most case reports show pulmonary artery catheters to be the most common victims. Excessive manipulation without fluoroscopy can lead to such complications. In the current era knotting is most commonly seen during radial catheterisation.

\section{Learning points}

- Knotting of temporary pacemaker leads can be avoided by careful visual control under fluoroscopy while inserting.

- Knotting is a significant cause of morbidity.

- If knotting ever happens, unknotting can be performed successfully by percutaneous methods. 


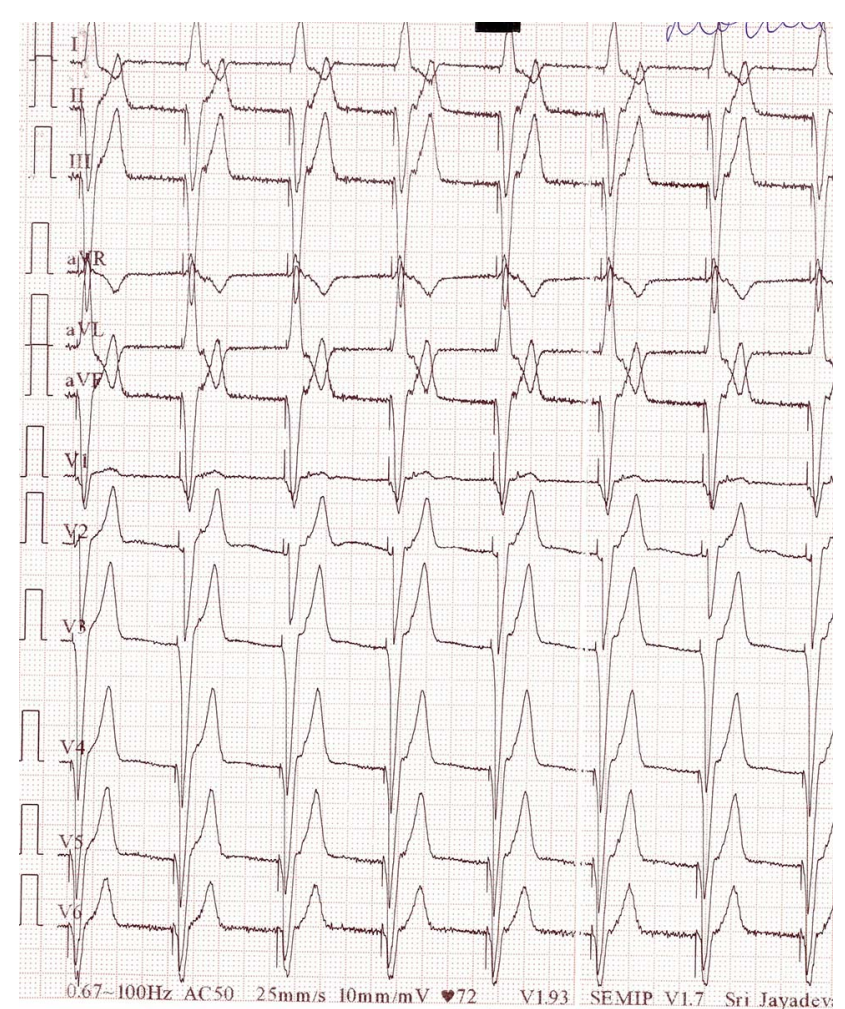

Figure 2 Twelve-lead ECG post-transjugular temporary pacing.

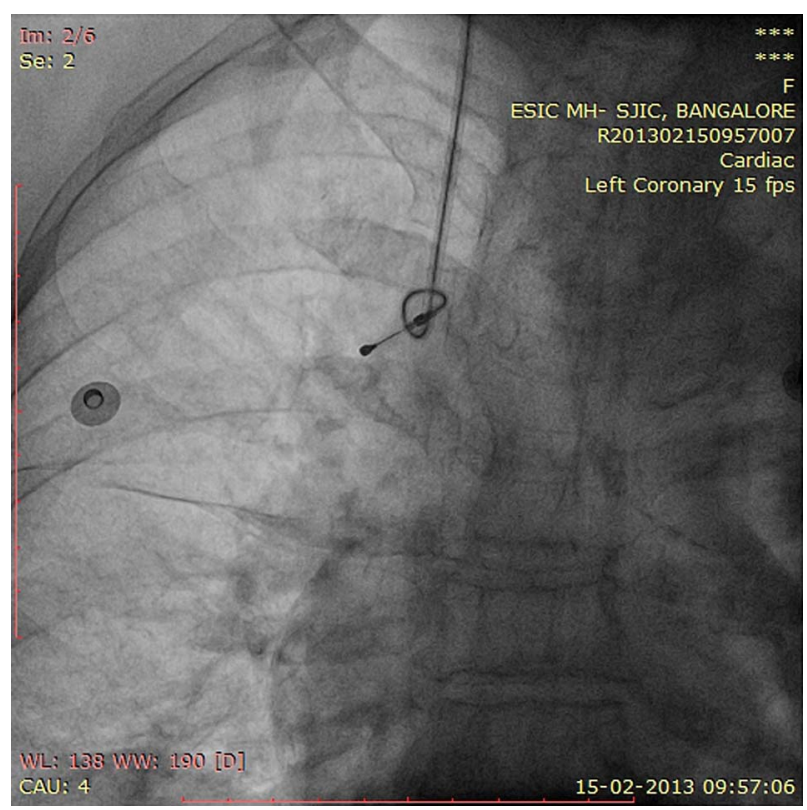

Figure 3 Flouroscopy anteroposterior view with a knot in the lead.

Acknowledgements The authors are thankful to Dr Neha Godara for moral support and help.

Contributors HM was involved in writing the article. SKKR and DR developed the idea of writing a case report and performed the procedure. CNM provided the finishing touches and was involved in obtaining all the required permissions.

Competing interests None.

Patient consent Obtained.

Provenance and peer review Not commissioned; externally peer reviewed.

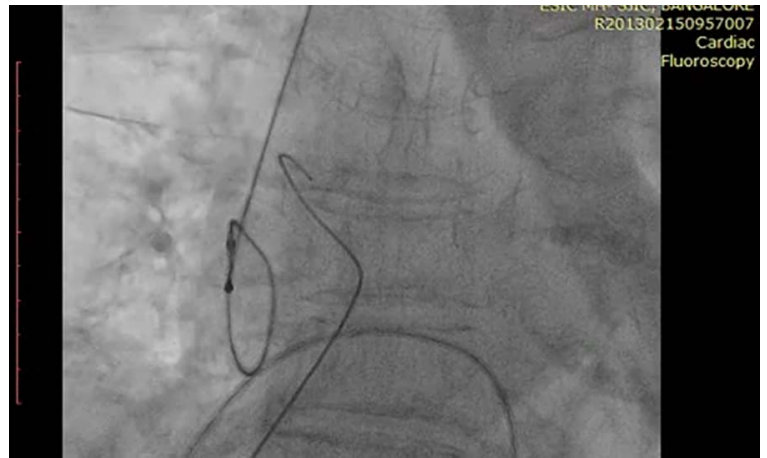

Video 1 Flouroscopy AP view with a knot in the lead.

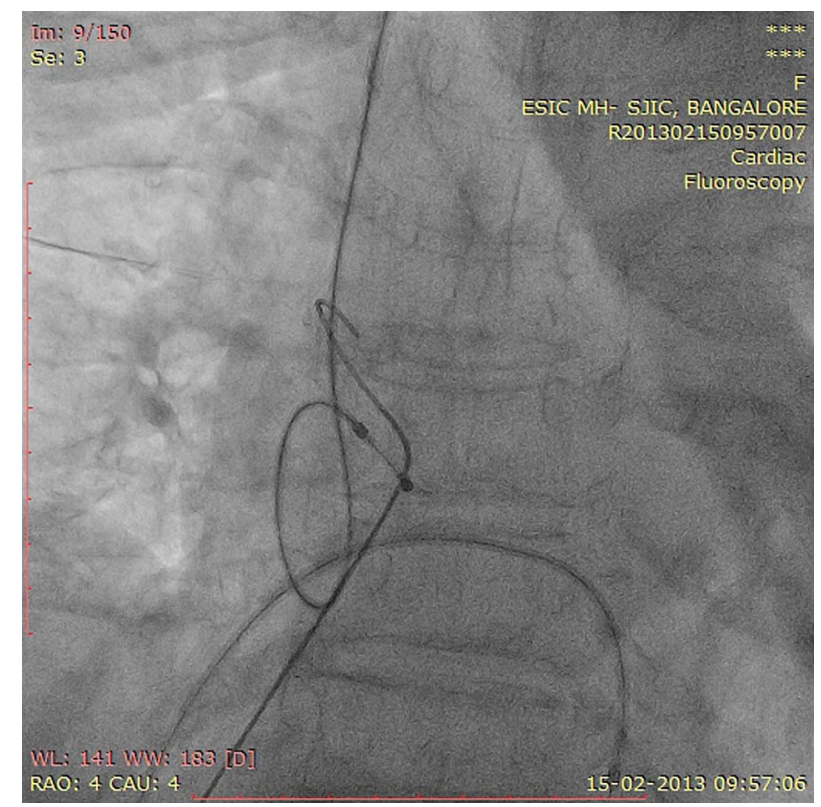

Figure 4 Flouroscopy anteroposterior view postpartially opened knot with J tipped wire side-by-side.

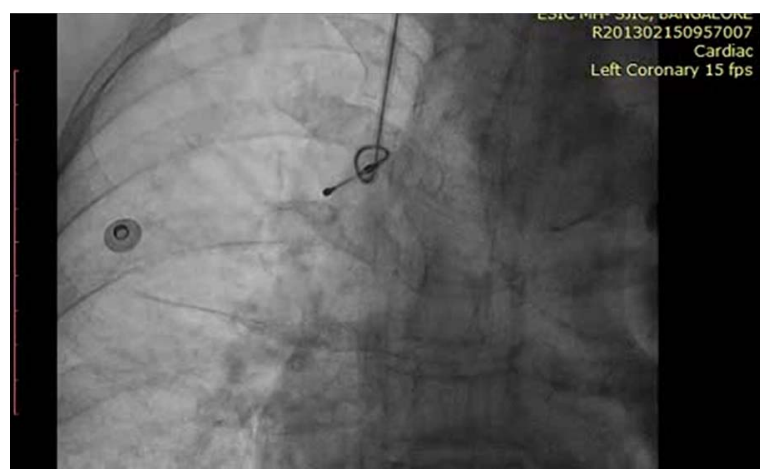

Video 2 Flouroscopy AP view post partially opened knot with J tipped wire side by side and retrieval of lead.

\section{REFERENCES}

1 Johansson L, Malmstrom G, Uggla LG. Intracardiac knotting of the catheter heart catheterization. J Thoracic Surg 1954;27:605-7.

2 Boal BH, Keller BD, Ascheim RS, et al. Complication of intracardiac electrical pacing -knotting together of temporary and permanent electrodes. $N$ Engl J Med 1969;280:650-1.

3 Patel R, Kumar S, Hameedi S. Nonsurgical removal of a kinked right coronary catheter. Angiology 1984;35:601-3. 
Copyright 2014 BMJ Publishing Group. All rights reserved. For permission to reuse any of this content visit http://group.bmj.com/group/rights-licensing/permissions.

BMJ Case Report Fellows may re-use this article for personal use and teaching without any further permission.

Become a Fellow of BMJ Case Reports today and you can:

- Submit as many cases as you like

- Enjoy fast sympathetic peer review and rapid publication of accepted articles

- Access all the published articles

- Re-use any of the published material for personal use and teaching without further permission

For information on Institutional Fellowships contact consortiasales@bmjgroup.com

Visit casereports.bmj.com for more articles like this and to become a Fellow 